\title{
RECOMMENDATIONS FOR SPORT AND PHYSICAL ACTIVITY AFTER TOTAL HIP AND KNEE ARTHROPLASTY: A SYSTEMATIC REVIEW
}

\author{
LORAND VITALIS ${ }^{1}$, OCTAV RUSSU ${ }^{2}$, SANDOR ZUH ${ }^{3}$, TUDOR SORIN POP ${ }^{4}$ \\ 1,2,3,4 Mureș Clinical County Hospital, 2,3,4 “George Emil Palade” University of Medicine, Pharmacy, Science, and Technology of Târgu Mureș
}

\begin{abstract}
Keywords: sports and joint replacement, total hip arthroplasty, total knee arthroplasty
\end{abstract}

\begin{abstract}
Due to the high success of arthroplasty, patients suffering from osteoarthritis have higher expectations regarding the relief of pain, functional recovery and capacity to perform physical and sports activity. The purpose of our article is to present a literature review based on papers published during the last decades, with emphasis on the current recommendations regarding sports after total joint replacement. We conducted a search using PubMed/Medline databases, selecting the scientific articles published between 2005-2020 which discuss the association between physical activity and total hip or knee arthroplasty. The benefits of physical activity in all kinds of joint prostheses outweigh the negative effects; therefore, the recommendation for low-impact sports (hiking, swimming, cycling or golf) at a moderate intensity is considered valid and patients with total hip or knee arthroplasty who preoperatively had a high level of physical activity can return to low-impact sports performed at moderate intensity after 3-6 months.
\end{abstract}

\section{INTRODUCTION}

The joint replacement surgery has received recognition as a very successful intervention and is indicated in advanced stages of hip and knee osteoarthritis, in order to offer pain relief, to correct deformities, to re-establish the function and finally to improve the quality of life of these patients.(1,2) Usually, these are older sedentary adults, with comorbidities such as overweight or obesity, high blood pressure or diabetes. In these cases, regular physical activity could have a beneficial effect on the general health and therefore total joint arthroplasty (TJA) could contribute to this outcome, as it facilitates not only the relief of pain, but also an increased sport activity. $(3,4)$

During the last decade, a lower tolerance to joint discomfort in cases with less advanced osteoarthritis and an increased demand for arthroplasties in younger patients have been recorded, factors considered responsible for the increased number of joint replacements worldwide, with around 500000 such interventions yearly. Beside pain, considered as a primary indication, more patients are preoccupied by being able to maintain a high level of physical activity and a healthy lifestyle.(5-7) As a consequence, specialists were forced to quantify the amount of sport activity allowed to be performed after TJA and also to establish the acceptable kinds of activities. Postoperatively, patients are advised to regain an active lifestyle which not only promotes their general health but also favours an adequate bone quality at the interface with the implant and reduces the risk of early loosening. $(8,9)$ However, defining the beneficial level of physical activity and predicting its outcomes proved to be a difficult task. For example, jogging was shown to increase the load on the hip joint to more than $500 \%$ of the body weight and high joint loads might lead to implant wear, debris, periprosthetic osteolysis and finally implant failure.(10) Scientific data suggests that during the last decades there was an increasing number of allowed physical activities, although not all surgeons shared the same opinion and therefore changed the indications over the years. $(11,12)$ The intensity of physical activity continues to be a matter of intense debate in the scientific literature, in an effort to distinguish between favourable and dangerous levels of sport activity that might jeopardize the long-term success of TJA.(13)

\section{AIM}

The aim of our review is to summarize the current recommendations for sports and physical activity in patients with TJA, in order to provide surgeons up-to-date guidelines regarding a rapid return to an active lifestyle, based on the existing scientific evidence.

\section{MATERIALS AND METHODS}

We conducted a search of scientific articles published in the time span 2005-2020, discussing the association between physical activity and TJA, using PubMed/Medline databases. As key words we used: physical activity, hip and knee arthroplasty, sports after joint replacement. From a total of 114 articles, we selected 33 original and review articles. The inclusion criteria for studies were: assessment of physical activity pre- and postoperatively, longitudinal design, recommendation for physical activity or sports in patients with TJA. The exclusion criteria for studies were: evaluation of the range of motion, intensity of pain, quality of life TJA, but with no reference to physical activity.

\section{TOTAL JOINT ARTHROPLASTY AND SPORTS}

Current interventions for TJA have a mean longevity of over $90 \%$ at $10-20$ years, therefore the minimum follow-up period for the assessment of clinical and radiological success of this procedure is 10 years, a time period after which most complications start to appear.(5,13) Based on an analysis

${ }^{2}$ Corresponding author: Octav Russu, Str. Mihai Viteazu, Nr. 31, Târgu Mureș, România, E-mail: octav.russu@umfst.ro, Phone: +40744 266735 Article received on 01.02.2021 and accepted for publication on 02.03.2021 


\section{CLINICAL ASPECTS}

conducted in Sweden on 92675 hip arthroplasties and 30003 knee arthroplasties, the rates of revision after 10 years for patients aged less than 55 and 65 years respectively were significantly higher $(20 \%$ and $18 \%$, respectively) than in older patients (5\% and $6 \%$, respectively). This could have been correlated to the higher level of physical activity of the younger patients.(1)

During physical activity, the increased force exerted through the prosthesis can represent an important risk factor for early failure, as it determines a high stress and wear between prosthetic components and also at the interface with the bone, inducing early loosening and implant instability. Beside material properties of the prosthetic components, the load force exerted on the implant is very important, as it can increase exponentially the amount of wear. Therefore, only activities such as swimming, power walking or cycling, characterized by low joint loads should be recommended.(14)

Scientific data suggested that physical inactivity might increase the risk of early loosening ( $<10$ years) as a result of insufficient osseointegration of non-cemented implants and osteopenia. On the other hand, an increased physical activity is associated with polyethylene wear and delayed loosening ( $>10$ years), due to reactive particle release and osteolysis.(15)

However, regarding the longevity of a new joint, there is no scientific evidence for the type and level of physical activity to be recommended or avoided after TJA. $(5,10)$ For each patient with TJA, the recommendations for a specific sport or physical activity must take into consideration the type of implant, but also the joint load and wear, as the reduction of these factors are the most important in the successful long-term results of the surgical intervention. Therefore, the goal is to find a balance that guarantees the benefits of physical activity and at the same time does not reduce the longevity of the prosthesis.(16)

\section{TOTAL HIP ARTHROPLASTY}

During the last decade, the number of total hip arthroplasties increased dramatically and it is estimated that the number of these interventions will exceed 575000 every year. Another observation was related to patient's demographic characteristics, with an increase of 50\% of patients aged 50-59 years old, who expect to return to high levels of physical activity after surgery. Most available data on the type of sports recommended after total hip arthroplasty (THA) comes from surveys based on clinical experience and preferences of surgeons and not from retrospective or prospective analyses.(17,18) Data collected in 2007 from 614 surgeons showed that low-impact activities were mostly recommended (swimming, stationary biking, dancing, bowling, walking).(10) Other activities such as pilates, downhill skiing, ice-skating or weightlifting were allowed with experience. The general consensus was that jogging, squash, contact sports, high impact aerobic, snowboarding and baseball/softball were not allowed. (table no. 1).(13)

Table no. 1. Physical activity and sports recommended after total hip arthroplasty

\begin{tabular}{|c|c|c|}
\hline $\begin{array}{c}\text { NOT } \\
\text { recommended }\end{array}$ & $\begin{array}{c}\text { Recommended with } \\
\text { experience }\end{array}$ & Recommended \\
\hline Singles tennis & Cross-country skiing & Doubles tennis \\
\hline Jogging/running & Downhill skiing & Swimming \\
\hline $\begin{array}{c}\text { Contact sports } \\
\text { football, hockey) }\end{array}$ & Weight lifting & $\begin{array}{c}\text { Low-impact aerobics } \\
\text { Weight machines }\end{array}$ \\
\hline High impact aerobic & Ice skating & Cycling, Elliptical \\
\hline Martial arts & Pilates & Speed walking, Golf \\
\hline Handball & & Dancing \\
\hline Waterskiing & & Hiking \\
\hline
\end{tabular}

(Adapted from Vogel et al) (13)
The time interval after which patients could return to allowed physical activity was estimated at 3 to 6 months after surgery, but about $30 \%$ of the specialists considered that $1-3$ months after THA is an acceptable time interval.(19,20) In a study from 2009, Swanson et al (15) analysed the answers from 139 surgeons regarding the allowance of these physical activities, grouped as unlimited, occasional (1-2 times/month) and discouraged. The results showed that the low impact sports were indicated unlimited (swimming, golf, walking, cycling, doubles tennis), while activities such as sprinting, jogging, and skiing difficult terrain were discouraged by most of the respondents. In 2012, Delasotta et al (21) reported their results regarding the participation of patients with THA to physical activities based on the recommendations stated by Klein et al in their survey from 2007.(10) The included patients declared that high impact sports were avoided not as a result of pain, lack of interest or fatigue but due to fear $(28.6 \%)$ or surgeon indications $(25.7 \%)$

Abe et al (22) confirmed that fear was an important factor that prevented $61 \%$ of patients with hip resurfacing, which is a more conservative surgical procedure, from returning to jogging, while only $15 \%$ avoided it due to pain. This data was confirmed by Huch et al (23) who reported that $56 \%$ of patients with THA gave up participating to sports "as a precaution, to go easy on the artificial joint." The authors considered that the fear of movement was an important issue, influenced by the postoperative education of the patient in adopting a healthy lifestyle. However, in a questionnaire retrospective study, Jassim et al (24) considered that the avoidance of intense physical activity after THA has a multi-factorial etiology. There are few prospective studies on the correlation between high levels of physical activities (considered a risk factor for dislocation, loosening, periprosthetic fracture, polyethylene wear) and poor clinical outcomes after THA. There is some evidence suggesting that wear may be related to activity level, but the impact on clinical outcomes was conflicting. $(25,26)$

\section{TOTAL KNEE ARTHROPLAST}

Knee osteoarthritis restricts the usual activity of a person, reducing the sports capacity and working but this condition can be treated by arthroplasty, a reliable and well accepted intervention; however, little information is available regarding the extent to which the patients can return to normal physical activity and sports. $(27,28)$ As a consequence of overwhelming data indicating that the lack of physical activity favours the onset of serious health problems, people became aware of the importance of staying physically active. In Europe, the number of osteoarthritis patients is expected to rise exponentially until 2040, with an increase in knee arthroplasties of $297 \%$, up to 57900 new cases annually in 2030.(29)

The indications for surgical intervention in knee osteoarthritis became broader due to better techniques and implants. A survey based on a questionnaire conducted by $\mathrm{Vu}$ Han et al (14) aimed to find the current recommendations, type of implant and surgical technique selected by the specialists when treating younger patients who have high expectations after surgery in terms of sports level. The results showed that within 3-6 months after surgery most surgeons indicated low-impact sports, while fewer considered that also high-impact sport is recommended. However, the answers regarding the choice of the surgical method or implant design were considered controversial and the authors presented no clear conclusions (table no. 2). In a systematic review, Witjes el al (30) considered that physical activity was possible after unicondylar and total knee arthroplasty (TKA) in $36-100 \%$ of patients, who returned to physical activity in about $12-13$ weeks and chose in $90 \%$ of the cases lower-impact sports. The authors concluded that 


\section{CLINICAL ASPECTS}

higher-impact physical activity is more appropriate after unicondylar arthroplasty.

Table no. 2. Physical activity and sports recommended after total knee arthroplasty

\begin{tabular}{|c|c|c|}
\hline NOT recommended & $\begin{array}{c}\text { Recommended } \\
\text { with experience }\end{array}$ & Recommended \\
\hline $\begin{array}{c}\text { Contact sports } \\
\text { (football, hockey) }\end{array}$ & Cycling & $\begin{array}{c}\text { Low impact } \\
\text { aerobics }\end{array}$ \\
\hline Rock climbing & Hiking & Dancing \\
\hline Singles tennis & Doubles tennis & Walking \\
\hline Running/ Jogging & Speed walking & Swimming \\
\hline Handball & Ice skating & Bowling \\
\hline Martial arts & Skiing & Golf \\
\hline
\end{tabular}

The evaluation was based on studies that gave little attention to parameters such as preoperative level of sports (considered important in quantifying the return to physical activity), comorbidities or restrictions from the surgeon. In order to make proper recommendation after TKA, it is important to evaluate the load and the knee flexion angle of the peak load; during jogging or hiking, high joint loads are present during knee flexion of $40-60^{\circ}$, angles at which in many implants designs polyethylene stress occurs. If performed regular, these physical activities rise the risk of delamination and polyethylene destruction for most current total knee implants. Therefore, it is advisable to be more conservative after TKA for sports that induce high joint loads in knee flexion.(31-33)

\section{CONCLUSIONS}

There is a significant discrepancy between previous expert recommendations and the actual activity levels that may be achieved after the implantation of a joint prosthesis. Future studies have to define the sports level, the type of sports and the type of prosthesis that provide a positive benefit-risk ratio using state-of-the-art low-abrasion bearing surfaces and prosthesis designs. It is important to recommend appropriate activities after TJA, being unwise to indicate technically demanding sports, which might represent a risk factor for injuries, especially in untrained individuals. Patients should be motivated to return to physically activity for their overall health and also for maintaining an adequate quality of bone, which facilitates prosthesis fixation and prevents early loosening. When recommending a certain activity after TJA one should take into consideration multiple factors such as wear, joint load, intensity and the type of implant in each particular case. However, the reduction of wear remains of utmost importance in the long-term success of TJA.

\section{REFERENCES}

1. Moura DL, Fonseca FP. Sports activity and hip, knee, shoulder and intervertebral disc arthroplasties. Acta Ortop Bras. 2018;26(5):350-5.

2. Wylde V, Blom A, Dieppe P, Hewlett S, Learmonth I. Return to sport after joint replacement. J Bone Joint Surg Br. 2008;90(7):920-3

3. Waldstein W, Kolbitsch P, Koller U, Boettner F, Windhager R. Sport and physical activity following unicompartmental knee arthroplasty: a systematic review. Knee Surg Sports Traumatol Arthrosc. 2017;25(3):717-28.

4. Bauman S, Williams D, Petruccelli D, Elliott W, de Beer J. Physical activity after total joint replacement: a crosssectional survey. Clin J Sport Med. 2007;17(2):104-8.

5. Healy WL, Sharma S, Schwartz B, Iorio R. Athletic activity after total joint arthroplasty. J Bone Joint Surg Am. 2008;90(10):2245-52.

6. Learmonth ID, Young C, Rorabeck C. The operation of the century:

total

hip

replacement.

Lancet. 2007;370(9597):1508-19.

7. Walker T, Streit J, Gotterbarm T, Bruckner T, Merle C, Streit MR. Sports, Physical Activity and Patient-Reported Outcomes After Medial Unicompartmental Knee Arthroplasty in Young Patients. J Arthroplasty. 2015;30(11):1911-6.

8. Levine B, Kaplanek B, Jaffe WL. Pilates training for use in rehabilitation after total hip and knee arthroplasty: a preliminary report. Clin Orthop Relat Res. 2009;467(6):1468-75.

9. Liebs TR, Herzberg W, Ruther W, Haasters J, Russlies M, Hassenpflug J. Ergometer cycling after hip or knee replacement surgery: a randomized controlled trial. J Bone Joint Surg Am. 2010;92(4):814-22.

10. Klein GR, Levine BR, Hozack WJ, Strauss EJ, D'Antonio JA, Macaulay W, Di Cesare PE. Return to athletic activity after total hip arthroplasty. Consensus guidelines based on a survey of the Hip Society and American Association of Hip and Knee Surgeons. J Arthroplasty. 2007;22(2):171-5.

11. Hoorntje A, Janssen KY, Bolder SBT, Koenraadt KLM, Daams JG, Blankevoort L, et al. The Effect of Total Hip Arthroplasty on Sports and Work Participation: A Systematic Review and Meta-Analysis. Sports Med. 2018;48(7):1695-1726.

12. Naal FD, Impellizzeri FM. How active are patients undergoing total joint arthroplasty? A systematic review. Clin Orthop Relat Res. 2010;468(7):1891-1904.

13. Vogel LA, Carotenuto G, Basti JJ, Levine WN. Physical activity after total joint arthroplasty. Sports Health. 2011;3(5):441-50.

14. Vu-Han TL, Gwinner C, Perka C, Hardt S. Recommendations for Patients with High Return to Sports Expectations after TKA Remain Controversial. J Clin Med. 2020 Dec 26;10(1):54

15. Swanson EA, Schmalzried TP, Dorey FJ. Activity recommendations after total hip and knee arthroplasty: a survey of the American Association for Hip and Knee Surgeons. J Arthroplasty. 2009;24(6 Suppl):120-6.

16. Fawaz WS, Masri BA. Allowed Activities After Primary Total Knee Arthroplasty and Total Hip Arthroplasty. Orthop Clin North Am. 2020;51(4):441-52.

17. Arbuthnot JE, McNicholas MJ, Dashti H, Hadden WA. Total hip arthroplasty and the golfer: a study of participation and performance before and after surgery for osteoarthritis. J Arthroplasty. 2007;22(4):549-52

18. Sechriest VF 2nd, Kyle RF, Marek DJ, Spates JD, Saleh KJ, Kuskowski M. Activity level in young patients with primary total hip arthroplasty: a 5-year minimum followup. J Arthroplasty. 2007;22(1):39-47.

19. Meek RMD, Treacy R, Manktelow A, Timperley JA, Haddad FS. Sport after total hip arthroplasty: undoubted progress but still some unknowns. Bone Joint $\mathrm{J}$. 2020;(6):661-3.

20. Ortmaier R, Pichler H, Hitzl W, Emmanuel K, Mattiassich G, Plachel F, et al. Return to Sport After Short-Stem Total Hip Arthroplasty. Clin J Sport Med. 2019;29(6):451-8.

21. Delasotta LA, Rangavajjula AV, Porat MD, Frank ML, Orozco FR, Ong AC. What are young patients doing after hip reconstruction? J Arthroplasty. 2012;27(8):15181525.e2.

22. Abe H, Sakai T, Nishii T, Takao M, Nakamura N, Sugano N. Jogging after total hip arthroplasty. Am J Sports Med. 2014;42(1):131-7.

23. Huch K, Müller KAC, Stürmer T, Brenner H, Puhl W, Günther K-P. Sports activities 5 years after total knee or hip arthroplasty: the Ulm Osteoarthritis Study. Ann Rheum 
Dis. 2005;64(12):1715-20.

24. Jassim SS, Tahmassebi J, Haddad FS, Robertson A. Return to sport after lower limb arthroplasty - why not for all? World J Orthop. 2019;10(2):90-100.

25. Affatato S, De Mattia JS, Bracco P, Pavoni E, Taddei P. Does cyclic stress and accelerated ageing influence the wear behavior of highly crosslinked polyethylene? J Mech Behav Biomed Mater. 2016;59:418-29.

26. Meftah M, Klingenstein GG, Yun RJ, Ranawat AS, Ranawat CS. Long-term performance of ceramic and metal femoral heads on conventional polyethylene in young and active patients: a matched-pair analysis. J Bone Joint Surg Am. 2013;95(13):1193-7.

27. Marker DR, Mont MA, Seyler TM, McGrath MS, Kolisek FR, Bonutti PM. Does functional improvement following TKA correlate to increased sports activity? Iowa Orthop J. 2009;29:11-6.

28. Mont MA, Marker DR, Seyler TM, Jones LC, Kolisek FR, Hungerford DS. High-impact sports after total knee arthroplasty. J Arthroplasty. 2008;23(6) (suppl 1):80-4.

29. Kanavaki AM, Rushton A, Efstathiou N, Alrushud A, Klocke R, Abhishek A, et al. Barriers and facilitators of physical activity in knee and hip osteoarthritis: a systematic review of qualitative evidence. BMJ Open. 2017;7(12):e017042.

30. Witjes S, Gouttebarge V, Kuijer PP, van Geenen RC, Poolman RW, Kerkhoffs GM. Return to Sports and Physical Activity After Total and Unicondylar Knee Arthroplasty: A Systematic Review and Meta-Analysis. Sports Med. 2016;46(2):269-92.

31. Nilsdotter AK, Toksvig-Larsen S, Roos EM. Knee arthroplasty: are patients'expectations fulfilled? A prospective study of pain and function in 102 patients with 5-year follow-up. Acta Orthop. 2009;80(1):55-61.

32. Argenson JN, Parratte S, Ashour A, Komistek RD, Scuderi GR. Patient reported outcome correlates with knee function after a single-design mobile bearing TKA. Clin Orthop Relat Res. 2008;466(11):2669-76.

33. Jackson JD, Smith J, Shah JP, Wisniewski SJ, Dahm DL. Golf after total knee arthroplasty: do patients return to walking the course? Am J Sports Med. 2009;37(11):22014. 